\title{
Dificuldades de aprendizagem em escrita e compreensão em leitura
}

\author{
Karla Aparecida Zucoloto \\ Pontifícia Universidade Católica, Poços de Caldas \\ Fermino Fernandes Sisto \\ Universidade São Francisco
}

\begin{abstract}
Resumo
Este trabalho teve como objetivo investigar a compreensão da leitura de crianças com dificuldade de aprendizagem escrita, em relação ao gênero e idade. Os participantes foram 194 alunos de $2^{\text {a }}$ e $3^{\text {a }}$ séries de uma escola pública de periferia de Poços de Caldas. Os alunos foram categorizados por níveis de dificuldade de aprendizagem em escrita segundo o instrumento Adape. A compreensão da leitura foi avaliada por dois textos em cloze, com diferentes quantidades de omissões. Os resultados mostraram que na segunda e terceira séries os erros na compreensão da leitura aumentavam em razão da dificuldade de aprendizagem da escrita e que os mais velhos apresentavam mais erros do que os mais novos, sendo que o gênero não indicou relações significativas. As tendências dos alunos de $2^{\mathrm{a}} \mathrm{e}$ $3^{\text {a }}$ séries foram similares, com a diferença de que na terceira série eles podem estar apresentando automatismo dos erros.
\end{abstract}

Palavras-chave: dificuldade de aprendizagem na escrita; compreensão de leitura; séries iniciais do ensino fundamental.

\begin{abstract}
Learning disabilities in writing and reading comprehension

This study aimed to investigate the difficulties of reading comprehension faced by some children in learning the written language. 194 second and third grade students from a public school in the suburbs of Poços de Caldas were studied. The students were ranked according to the learning difficulties they had in written language by the ADAPE test. The reading comprehension was evaluated in two texts in cloze procedure, which presented different numbers of blanks. The results showed that in the second and third grades the mistakes in reading comprehension increased according to the written learning difficulties, and that older students made more mistakes than the younger ones. Besides, the genre did not present statistically significant relations. The tendencies of both second and third grades were similar, although the third grade students are making a habit of repeating the errors.

Keywords: learning disabilities in writing; reading comprehension; initial school grades.
\end{abstract}

\section{INTRODUÇÃO}

Muitas crianças aprenderão a ler e escrever e não encontrarão nenhuma dificuldade, e outras necessitarão de alguma ajuda especial para conseguir sucesso na mesma atividade. $\mathrm{O}$ fracasso escolar nas primeiras séries do ensino fundamental tem sido estudado pelos mais diversos profissionais preocupados com a escola, na busca de se explicitar os fatores que interferem no sucesso escolar e melhorar o ensino público no Brasil. As pesquisas se apóiam em fatores sociais, culturais, econômicos, cognitivos emocionais, institucionais ou orgânicos para explicar o fracasso escolar (Schiefelbein \& Simmons, 1990; Cardoso-Martins, 1991; Brandão, 1992; Oliveira, Sisto, Souza, Brenelli \& Fini, 1994; Vieira, 1998; Leffa, 1999; Capellini \& Ciasca, 2000, entre outros); outras na metodologia de ensino e avaliação (Nunes, 1990).
Não existe uma definição comum sobre o que vem a ser uma dificuldade de aprendizagem, como e por que ela se manifesta. As dificuldades de aprendizagem formam um grupo heterogêneo e é difícil defini-las, mas uma das manifestações mais evidentes de dificuldade de aprendizagem é o baixo rendimento, o que não necessariamente indica que a criança tenha dificuldade de aprendizagem. Podem ser categorizadas como transitórias ou permanentes e ocorrer a qualquer momento no processo de ensino-aprendizagem e correspondem a déficits funcionais superiores, tais como, cognição, linguagem, raciocínio lógico, percepção, atenção e afetividade (Bermejo \& Llera, 1997; Dockrell \& McShanne, 1997, Garcia, 1998).

A leitura e a escrita são as formas de linguagem mais avaliadas pelo ensino fundamental. Elas são a base para a avaliação escolar. Ambas implicam um 
duplo sistema simbólico, pois permitem transcrever um equivalente visual em um equivalente auditivo, ou o contrário.

A leitura é considerada um sistema simbólico, alicerçado na linguagem falada, que por sua vez depende da linguagem interior. A relação entre a palavra escrita e o sistema simbólico de significação é uma operação cognitiva que envolve processos específicos como a codificação, decodificação, percepção, memória, entre outros. Para a pessoa decodificar e atribuir significado ao que está escrito é preciso ativar sua estrutura representativa, atribuir significado ao código de modo a reconhecer a palavra impressa, atribuir a essa palavra o significado correspondente e compreender a mensagem (Coll, Palacios \& Marchesi, 1995; Garcia, 1998, Capovilla, 2000). Também, é preciso coordenar as informações de modo a conseguir interpretar a mensagem dentro de um contexto, pois a compreensão da leitura implica o reconhecimento das estruturas gramaticais, a consideração da ordem das palavras, o papel funcional das palavras, o reconhecimento e o uso dos sinais de pontuação. Nesse contexto, a compreensão da leitura tem a ver com a capacidade de fazer inferências, recorrendo a elementos mencionados no próprio texto.

As dificuldades de leitura implicam normalmente uma falha no reconhecimento, ou a compreensão do material escrito. O reconhecimento é o mais básico dos processos, já que o reconhecimento de uma palavra é prévio a sua compreensão. Também há que se considerar que uma decodificação pobre leva a uma compreensão pobre; entretanto, uma boa decodificação não é a garantia de compreensão. As dificuldades de compreensão não estão, normalmente, no âmbito das palavras, e sim, no âmbito de orações e da integração da informação das orações (Dockrell \& McShane, 1997).

As pesquisas sobre a leitura são diversificadas. A leitura aparece em temas de pesquisa tais como hábito de leitura e compreensão de textos (Santos, 1981); identificação da palavra no contexto (Vellutino, 1991); programas de remediação (Dias, Morais \& Oliveira, 1995; Batjes \& Brown, 1997); dificuldades na leitura (Lyon, 1998); a compreensão de leitura em textos argumentativos, explicativos e narrativos (Vieira, 1998); a leitura e seu contexto (Leffa, 1999); a transição de leitura oral para leitura silenciosa (Kragler, 1995); o processo da leitura e sua importância (Brandão, 1992), entre outros.

Por sua vez, a escrita é um processo complexo, que envolve habilidades diferentes da leitura, mas que implica, na construção da mesma estrutura, a representação cognitiva.

Segundo Garcia (1998) pode-se analisar a escrita no ditado, forma que foi utilizada nesta pesquisa, com base na análise acústica dos sons por meio da qual os fonemas componentes da palavra seriam identificados.
É a identificação do código. Segue-se com um reconhecimento das palavras e a atribuição de significado, para depois, ser ativada a forma ortográfica das palavras e os processos motores. É a atribuição de significado ao significante. Esse caminho supõe a compreensão do significado do que está escrito e a aferição da ortografia correta. Para escrever uma palavra que lhe foi ditada, o sujeito deverá ter construído a noção de letra, de número, de vogal, de consoante, de palavra e de frase. Além dessas construções, que implicam a construção do sistema de representação e na construção do código, o sujeito deverá dominar o sistema de significação, de modo a diferenciar significado e significante. Entretanto, Hayes e Flower (1980, citado por Bermejo \& Llera, 1997) preferem analisar o processo da escrita por três processos, a saber, construção da representação mental do que pretende escrever antes da ação, a transformação da representação mental em representação escrita mediante um determinado sistema de convenções linguiísticas e a revisão ou análise da representação escrita.

Escrever supõe tomada de decisões acerca do que vai ser escrito, como será escrito, que letras devem ser empregadas. Se alguém pede ao sujeito que escreva a palavra aniversário, ele terá que organizar as letras em um plano coerente e revisar o que foi escrito. Terá que lidar com diferenciações e negações para escrever, ou seja, diferenciar os signos entre si e excluir as letras que não devem ser utilizadas. É um processo muito lento a princípio que vai se tornando automatizado com o tempo, e essa automatização implica economia de memória e atenção, simplificando a tarefa, ao mesmo tempo em que se torna extremamente rápido.

As dificuldades de aprendizagem em escrita podem se manifestar por confusão, inversão, transposição e substituição de letras, erros na conversão símbolosom, ordem de sílabas alteradas, lentidão na percepção visual, entre outros. Essas dificuldades podem se manifestar em áreas distintas como ao soletrar ou escrever uma palavra ditada.

A questão da escrita, bem menos pesquisada que a leitura, é abordada, principalmente, sob dois enfoques. Aparece relacionada à dificuldade (Deffenbaugh, 1977; Usova, 1978) e relacionada ao diagnóstico de crianças com problemas educacionais (Vinsonhaler, 1982).

A escrita, assim como a leitura, consiste em um conjunto de habilidades complexas, cujo processo requer que o indivíduo opere em diversos níveis de representação, sem deixar de lado o motor. Para ler e escrever é necessário que o sujeito possua a capacidade de realizar correspondências entre fonemas e grafemas. E a consciência sintática requer a capacidade de operar mentalmente sobre os mecanismos responsáveis pela representação das palavras, e dessas no seu contexto. Por sua vez, a consciência fonológica requer a capacidade de manipular as subunidades da linguagem falada, ou seja, fonemas e palavras. 
Assim, ler e escrever relacionariam duas significações e seriam interdependentes, pois a primeira levaria à segunda e vice-versa. Nesse contexto, a pesquisa e a observação de Whyte (1985) indicaram uma conexão entre leitura e escrita. A autora afirma que teóricos cognitivistas acreditam que a leitura e a escrita envolvem estruturas similares e que muitos pedagogos defendem o ensino da leitura e da escrita juntos e contextualizados.

$\mathrm{Na}$ literatura é possível encontrar autores pesquisando a leitura e a escrita sob diferentes enfoques. A questão da leitura e da escrita aparece relacionada à dificuldade de aprendizagem nos trabalhos de Thomas, Englert e Gregg (1987) e Berninger e Whitaker (1995). A consciência fonológica e a aprendizagem inicial da leitura e da escrita foram o objetivo da pesquisa de Cardoso-Martins (1991), cujos resultados mostraram que, de modo geral, as variações na consciência fonológica correlacionam-se com a aprendizagem da leitura e da escrita. Os resultados de Tiosso (1989) mostraram que as dificuldades na aprendizagem da leitura e da escrita não estavam relacionados com o potencial intelectual deficiente, assim como os achados neurológicos não justificavam tais dificuldades. Oliveira, Sisto, Souza, Brenelli e Fini (1994) pesquisaram os fatores que poderiam explicar o desempenho de crianças em um ditado. As crianças foram avaliadas em relação à tendência operatória, tendência criativa, psicomotricidade, leitura e compreensão da leitura, sendo que os dois últimos pareceram explicar melhor o desempenho ruim dos alunos. Um estudo desenvolvido por Capellini e Ciasca (2000) teve como objetivo avaliar a consciência fonológica de crianças com distúrbio específico de leitura e de escrita. Os resultados mostraram que as crianças com história de fracasso escolar apresentaram nível de leitura ortográfico, nível intelectual superior médio e bom nível de consciência fonológica. As autoras concluíram que o desenvolvimento da consciência fonológica ocorre concomitantemente com o processo de aprendizado da leitura. Por sua vez, Santos (2001) concluiu que a falta de consciência fonológica pode contribuir para uma vagarosa aquisição da habilidade de reconhecer palavras.

A quantidade de pesquisas dedicadas ao estudo da leitura é superior ao número encontrado de pesquisas sobre a escrita, levando a crer que o processo da escrita tem sido relativamente negligenciado pelos pesquisadores. A maior parte das pesquisas realizadas sobre a escrita concentra-se na ortografia, isto é, sobre a capacidade de recordar e reproduzir cadeias de letras aceitas como ortografia correta de determinada palavra. No entanto, poucos trabalhos abordam a leitura e a escrita como uma prática integrada, nos quais ambas determinam o sucesso ou o fracasso escolar com a mesma importância e amplitude.

Para a realização desta pesquisa, tomou-se por questão a relação entre a leitura e a escrita, porque no caso do português, cuja estrutura gramatical, além de ser complexa, possui muitas exceções, as dificuldades de aprendizagem em escrita podem decorrer de inúmeras combinações. É importante ressaltar que uma pessoa ler uma palavra corretamente não implica que possa grafá-la com precisão. Uma coisa é ler e outra coisa é escrever, muito embora as duas atividades possam se desenvolver, integrando-se. Assim, foram colocadas questões tais como: no início da escolarização, os bons leitores seriam bons escritores? Os alunos com baixa compreensão de leitura são os que apresentam dificuldade de aprendizagem na escrita?

\section{MÉTODO}

\section{Participantes}

Este trabalho foi desenvolvido em uma escola pública da periferia de Poços de Caldas, cujo nível socioeconômico foi considerado baixo. Participaram desta pesquisa 194 alunos de $2^{\mathrm{a}} \mathrm{s}$. e $3^{\mathrm{a}} \mathrm{s}$. séries. Das segundas séries foram estudados 49 meninas e 52 meninos com idades entre 7 e 16 anos, e nas terceiras séries, 47 meninas e 46 meninos com idades entre 8 e 18 anos.

Para efeito de análise foram formados dois grupos etários em ambas as séries. Na segunda série, a) o grupo dos mais novos, com 7 e 8 anos de idade e b) os mais velhos, com idades acima 9 anos. Na terceira série, a) o grupo de alunos mais novos, cujas idades estavam entre 8 e 9 anos; e b) o grupo de alunos mais velhos, com idades acima 10 anos.

\section{Instrumentos}

As provas foram respondidas de forma coletiva na própria sala de aula, no mês setembro. Primeiramente, foi aplicado um texto em cloze em todas as turmas, a seguir o ditado e, finalmente, quinze dias depois, foi aplicado o segundo texto em cloze, sempre pela professora da classe.

\section{a) Escrita}

Foi usado o instrumento ADAPE (Avaliação das Dificuldades de Aprendizagem em Escrita) para avaliar as dificuldades de aprendizagem da escrita (Sisto, 2001), que consiste em um ditado de um texto composto por 114 palavras, sendo 60 delas com algum tipo de dificuldade lingüística e outras 54 palavras sem essas dificuldades. Por meio dessa prova avaliamse encontros consonantais, dígrafos, sílabas complexas, sílabas compostas, uso correto do parágrafo e uso correto da letra maiúscula. Esse instrumento possui validade de critério e alta precisão.

As bases para a construção dos critérios de classificação dos níveis de dificuldades em escrita foram: a) distanciamento entre a pontuação de aquisição do instrumental da escrita e a pontuação da criança em razão da série que freqüenta; b) a necessidade de se ter pelo menos duas oportunidades para aprender a ler e 
escrever fez com que apenas a partir do segundo semestre do segundo ano do ensino fundamental fossem caracterizados indícios de dificuldades de aprendizagem; c) a formação do automatismo ou hábito em razão da repetição do erro, pois, quanto mais automática ficar a forma errada da escrita, mais o processo fica inconsciente e mais difícil torna-se sua correção (Sisto, 2001).

Os alunos foram categorizados, segundo o critério ADAPE. A escala do instrumento para segunda série é a seguinte: sem indícios de dificuldade de aprendizagem (DA) até 20 erros; dificuldade de aprendizagem (DA) leve, de 50 - 79 erros; e dificuldade de aprendizagem (DA) média, 80 ou mais erros. A escala para a terceira série é a seguinte: sem indícios de dificuldade de aprendizagem (DA) até 10 erros; dificuldade de aprendizagem (DA) leve, de 11 - 19 erros; dificuldade de aprendizagem (DA) média, 20-49 erros; e dificuldade de aprendizagem (DA) acentuada, 50 ou mais erros.

$\mathrm{Na}$ aplicação, foi explicado que seria efetuado um ditado de um texto, que as palavras seriam lidas uma a uma e não seriam repetidas, além de serem orientados para escrever todas as palavras. Foi entregue ao aluno uma folha em branco para que escrevesse o ditado. Cada uma das palavras foi considerada como um item ou uma unidade de medida para efeitos de pesquisa, atribuindo-se um ponto a cada erro.

\section{b) Leitura}

Em 1953 Taylor publica um novo instrumento denominado Técnica Cloze, consistindo na retirada sistemática de cada enésima palavra da mensagem. $\mathrm{O}$ teste em cloze foi estudado em relação à inteligibilidade dos textos, compreensão de leitura, tipos de teste, critério de correção, escalas de pontuação e tamanho das lacunas, cujos resultados indicam sua utilização (Weintraub, 1968; Garrido, 1979; Jongsma, 1980; Molina, 1984); como também para o desenvolvimento da compreensão em leitores (Santos; 1981; Braga 1986; Carelli, 1992; Joly, 1999; entre outros). No geral, a afirmação da capacidade do cloze foi embasada na correlação com outros instrumentos.

A técnica cloze foi usada como instrumento de diagnóstico, e para esta pesquisa adotou-se como critério suprimir a quinta palavra, mantendo intactas a primeira e a última frase. No lugar da palavra suprimida colocou-se uma lacuna de tamanho constante. O leitor preencheria as lacunas de modo a devolver o sentido ao texto, contando apenas com o contexto da mensagem. O primeiro texto ficou com dez lacunas e o segundo texto ficou com quinze lacunas. Na aplicação, solicitou-se que primeiro lessem o texto silenciosamente até o final e, em seguida, completassem as lacunas, garantindo o sentido ao texto. Não foi estipulado tempo para a realização da tarefa.
A análise da compreensão de leitura se deu em razão de três medidas: a) compreensão geral de leitura, produto da somatória de erros nos dois textos, b) erros em relação ao primeiro texto, com dez omissões, c) erros em relação ao segundo texto com quinze omissões. Para a correção dos textos em cloze a aceitação dos sinônimos mostrou-se viável, apesar de bastante polêmica (Rankin, 1975 e McKenna, 1976, citado por Santos, 1981), atribuindo-se 1 ponto para cada erro. O desempenho concernente à compreensão da leitura obteve-se pela soma dos erros. 


\section{RESULTADOS}

\section{A) Segunda série}

Gênero, dificuldade de aprendizagem em escrita e compreensão da leitura.

O número de alunos com dificuldade de aprendizagem leve em escrita, 34 alunos, foi muito próximo do número de alunos com dificuldade de aprendizagem média em escrita, 40 alunos. Uma minoria dessa série, 7 alunos, não apresentou dificuldade de aprendizagem, indicando que constituem exceção os alunos dessa série sem dificuldade em escrita. No intuito de se analisar as possíveis relações entre a dificuldade de aprendizagem em escrita, a compreensão da leitura e o gênero, utilizou-se o procedimento estatístico de análise de variância $(2 \times 3)$ e nível de significância $p=$ 0,05 .

Tabela 1 - Valores de F e p em relação ao gênero, dificuldade de aprendizagem em escrita e compreensão da leitura, na segunda série

\begin{tabular}{lc|c|c|c|c|c}
\hline & \multicolumn{2}{c|}{ Leitura geral } & \multicolumn{2}{c|}{ Primeiro texto } & \multicolumn{2}{c}{ Segundo texto } \\
\cline { 2 - 6 } & $\mathrm{F}$ & $\mathrm{p}$ & $\mathrm{F}$ & $\mathrm{p}$ & $\mathrm{F}$ & $\mathrm{p}$ \\
Dificuldade de aprendizagem & 19,762 & 0,000 & 12,099 & 0,000 & 21,251 & 0,000 \\
Gênero & 1,168 & 0,283 & 1,274 & 0,262 & 0,357 & 0,552 \\
Interação & 0,702 & 0,499 & 0,194 & 0,824 & 1,080 & 0,344 \\
\hline
\end{tabular}

Com relação à compreensão geral da leitura, só o nível de dificuldade de aprendizagem em escrita diferenciou o desempenho geral de leitura de forma significativa. Verificou-se que os alunos sem dificuldade de aprendizagem tiveram menos erros na compreensão da leitura (média de 7,71), enquanto que os alunos que apresentaram dificuldade de aprendizagem média tiveram mais erros na compreensão da leitura (média de 16,85). Além disso, como os alunos com dificuldade de aprendizagem leve em escrita tiveram uma média de 12,08 erros na compreensão da leitura, quando o máximo seria 25 erros, pôde-se inferir que a maioria desses alunos escreve com muitos erros e compreende pouco o que está lendo. Pôde-se perceber também que para esses alunos os textos não foram fáceis.

No primeiro texto, novamente apenas a dificuldade de aprendizagem em escrita foi significativa. Os alunos sem dificuldade de aprendizagem apresentaram a menor média de erros de compreensão $(3,14)$, seguidos dos alunos com dificuldade de aprendizagem leve (média de 4,58) e, finalmente, os alunos com média dificuldade (média de 6,72). Assim, seguiu-se a mesma tendência anterior, ou seja, conforme aumenta a dificuldade de aprendizagem na escrita, aumentam os erros na compreensão da leitura. Pode-se perceber que esse texto não foi de fácil leitura para esse grupo de crianças, pois a média de erros na compreensão da leitura foi 5,53 e o máximo seriam 10 .

No segundo texto, também apenas o nível de dificuldade de aprendizagem apresentou diferença significativa. A tendência observada foi a mesma anterior, e as médias de erros observadas foi de 4,57; 7,34 e 10,25 na ordem do menor para o maior nível de dificuldade. Para esse grupo de alunos o segundo texto não foi de fácil leitura, pois a média de erros foi de 8,63, sendo o máximo 15 erros.

Idade, dificuldade de aprendizagem em escrita e compreensão da leitura.

Tabela 2 - Valores de F e p em relação à idade, dificuldade de aprendizagem em escrita e compreensão da leitura, na segunda série

\begin{tabular}{lc|c|c|c|c|c}
\hline & \multicolumn{2}{c|}{ Leitura geral } & \multicolumn{2}{c|}{ Primeiro texto } & \multicolumn{2}{c}{ Segundo texto } \\
\cline { 2 - 7 } Dificuldade de aprendizagem & $\mathrm{F}$ & $\mathrm{p}$ & $\mathrm{F}$ & $\mathrm{p}$ & $\mathrm{F}$ & $\mathrm{p}$ \\
Idade & 5,354 & 0,007 & 5,111 & 0,008 & 6,607 & 0,002 \\
Interação & 7,233 & 0,009 & 0,860 & 0,357 & 13,235 & 0,000 \\
\hline
\end{tabular}

A primeira análise considerou o desempenho geral de leitura, cujos resultados indicam que são significativas a idade e a dificuldade de aprendizagem em escrita. Considerando que a relação entre dificuldade de aprendizagem em escrita e leitura já foi analisada anteriormente, comentar-se-á apenas os dados em relação à idade. $\mathrm{O}$ grupo dos alunos mais novos teve uma média de 11,40 erros na compreensão da leitura, 
e os alunos mais velhos tiveram uma média de 16,92 erros na compreensão leitura, indicando que a compreensão da leitura dos alunos mais velhos está mais comprometida do que a compreensão da leitura dos alunos mais novos.

Pela análise com o primeiro texto, somente a dificuldade de aprendizagem em escrita foi significativa e já analisada anteriormente. Com o segundo texto, foram significativas a idade e a dificuldade de aprendizagem em escrita. Em relação à idade, os alunos mais velhos apresentam mais erros de compreensão (média de 10,3636) que os alunos mais novos (média de 7,0816).

\section{B) Terceira série}

A maioria dos alunos desta série apresentou dificuldade de aprendizagem média em escrita e um grupo razoável, contudo, apresentou dificuldade de aprendizagem acentuada $(16,1 \%)$. Devido ao número restrito de alunos sem dificuldade de aprendizagem em escrita, para efeitos de análise, o grupo dos alunos sem indícios de dificuldade de aprendizagem foi aglutinado ao grupo dos alunos com dificuldade de aprendizagem leve, recebendo esta última denominação.

Gênero, dificuldade de aprendizagem em escrita e compreensão da leitura

Tabela 3 - Valores de F e p em relação ao gênero, dificuldade de aprendizagem em escrita e compreensão da leitura, na terceira série

\begin{tabular}{lc|c|c|c|c|c}
\hline & \multicolumn{2}{c|}{ Leitura geral } & \multicolumn{2}{c|}{ Primeiro texto } & \multicolumn{2}{c}{ Segundo texto } \\
\cline { 2 - 7 } & $\mathrm{F}$ & $\mathrm{p}$ & $\mathrm{F}$ & $\mathrm{p}$ & $\mathrm{F}$ & $\mathrm{p}$ \\
Dificuldade de aprendizagem & 3,697 & 0,029 & 1,366 & 0,261 & 3,946 & 0,023 \\
Gênero & 3,115 & 0,081 & 2,182 & 0,143 & 2,761 & 0,100 \\
Interação & 1,217 & 0,301 & 0,753 & 0,474 & 0,796 & 0,454 \\
\hline
\end{tabular}

Com relação à compreensão geral da leitura, só a dificuldade de aprendizagem em escrita mostrou-se significativa. Observou-se que os alunos com dificuldade de aprendizagem em escrita leve tiveram menos erros (média 7,10) que os alunos com dificuldade de aprendizagem acentuada (média 13,07). Considerando que o máximo de erros seria 25 , a média destes últimos alunos indica que sua maioria escreve com muitos erros e apresenta dificuldade para compreender o que está lendo. Pôde-se perceber que para esses alunos os textos não foram fáceis; a prova de escrita também não ofereceu facilidade.

Em relação à compreensão no primeiro texto, os valores não são significativos, e as diferenças encontradas foram atribuídas ao acaso. No segundo texto, somente a dificuldade de aprendizagem relacionou-se de forma significativa à compreensão da leitura desses alunos.

Os alunos com dificuldade de aprendizagem leve em escrita tiveram uma média de erros de 4,08; os alunos que apresentaram dificuldade de aprendizagem média tiveram uma média de erros de 5,60, e os alunos com dificuldade de aprendizagem acentuada, uma média de erros de 8,50. Vale pontuar que, nesse caso, a média de erros entre o nível leve e acentuado é o dobro. Para esse grupo de alunos o segundo texto não foi de fácil leitura, uma vez que a média de erros foi de 5,84, sendo o máximo 15 erros; assim, a terça parte da mensagem ficou fragmentada.

Idade, dificuldade de aprendizagem em escrita e compreensão da leitura

Tabela 4 - Valores de F e p em relação à idade, dificuldade de aprendizagem em escrita e compreensão da leitura, na terceira série

\begin{tabular}{lc|c|c|c|c|c}
\hline & \multicolumn{2}{c|}{ Leitura geral } & \multicolumn{2}{c|}{ Primeiro texto } & \multicolumn{2}{c}{ Segundo texto } \\
\cline { 2 - 7 } & $\mathrm{F}$ & $\mathrm{P}$ & $\mathrm{F}$ & $\mathrm{p}$ & $\mathrm{F}$ & $\mathrm{p}$ \\
Dificuldade de aprendizagem & 4,450 & 0,015 & 1,944 & 0,150 & 5,877 & 0,004 \\
Idade & 12,224 & 0,001 & 11,603 & 0,001 & 4,256 & 0,042 \\
Interação & 1,951 & 0,149 & 1,105 & 0,336 & 2,451 & 0,092 \\
\hline
\end{tabular}


Pela tabela 4 , em relação à compreensão geral de leitura, foram significativas a idade e a dificuldade de aprendizagem em escrita. Em relação à idade o grupo dos alunos mais velhos (média de 10,07 erros) apresenta mais erros do que os alunos mais novos (média de 7,52 erros). No primeiro texto, somente a idade foi significativa, sendo que os alunos mais novos apresentaram uma média de 2,25 erros na compreensão da leitura, e os alunos mais velhos apresentaram uma média de 4,05 erros na compreensão da leitura. A tendência continua mantida. Em relação ao segundo texto, foram significativas a idade e a dificuldade de aprendizagem. A compreensão da leitura dos alunos mais velhos apresenta mais erros (média de 6,62) do que a compreensão da leitura dos alunos mais novos (média de 5,23).

\section{DISCUSSÃO}

Este estudo buscou analisar as relações entre a leitura e a escrita que pudessem ser estabelecidas com alunos de segunda e terceira séries. A hipótese desta investigação esperava que o aluno com dificuldade de aprendizagem na escrita também poderia apresentar baixa compreensão da leitura. Os resultados indicaram que a dificuldade de aprendizagem em escrita está relacionada à compreensão da leitura e à idade, independendo da série.

Os dados apontaram que em ambas as séries os resultados para a dificuldade de aprendizagem em escrita e a compreensão da leitura não sofreram influências do gênero, e os erros na compreensão da leitura aumentaram conforme aumentou a dificuldade de aprendizagem em escrita. Ao lado disso, percebeu-se que os alunos que não apresentaram dificuldade de aprendizagem em escrita constituem exceção e que a maior parte deles se encaixou ou no nível leve ou no nível médio de dificuldade de aprendizagem em escrita. Esses dados denotam que a maioria desses alunos escreve com muitos erros e compreende pouco daquilo que lê. Por sua vez, com relação à leitura geral, pôde-se perceber que os alunos mais velhos apresentaram mais erros na compreensão da leitura do que os alunos mais novos. Assim, a compreensão da leitura desses alunos tende a se fragmentar, a fluência tende a diminuir, fazendo com que eles consigam retirar poucas informações do texto.

Quando os resultados encontrados em uma série foram comparados com os resultados obtidos para a outra série percebeu-se que o desempenho geral da segunda série foi inferior ao desempenho geral da terceira série, o que era esperado. Essas diferenças, contudo, se mostraram muito próximas, ou seja, o desempenho para a terceira série foi inferior ao previsto. Vale ressaltar a questão do automatismo do erro na terceira série, pois esses alunos já haviam passado por mais de dois anos completos de escolarização.

De todas as atividades presentes no ato da leitura a mais básica é que ao ler os signos são reconhecidos e lhes são atribuídos significados. Duas condutas distintas podem ser observadas nessa fase. Quando o aluno está diante de uma palavra conhecida age com rapidez, e o reconhecimento é instantâneo. Quando se encontra diante de uma palavra desconhecida, o reconhecimento se torna mais lento e pode tender a transformar em sons as unidades ortográficas que a compõem, dando lugar à pronúncia da palavra (Fonseca, 1995; Garcia, 1998). A compreensão da leitura exige a coordenação de uma ampla variedade de atividades, que podem ser condensadas em dois grandes grupos: atividades envolvidas em atribuir significado aos signos escritos e atividades que integram esses significados na compreensão da mensagem escrita (Coll, Palacios \& Marchesi, 1995). O mecanismo consiste em extrair o significado global da mensagem e ao mesmo tempo seguir organizando os significados locais. É um processo constante em que o aluno deve decodificar e juntar os significados entre si de modo global. Algumas possíveis causas para a baixa compreensão da leitura poderiam ser encontradas nesse âmbito, uma vez que muitas crianças poderiam ter deixado de resgatar o significado. Os dados encontrados mostraram que essa integração dos significados ofereceu muita dificuldade na compreensão dos textos em cloze, corroborando a posição de Vellutino (1991), sugerindo uma direção para outras pesquisas.

As crianças podem ter apresentado uma baixa compreensão da leitura pela ação de diferentes fatores, que podem ter atuado de forma conjunta ou isolada: dificuldade em diferenciar a forma visual-ortográfica dos signos escritos, podem ter apresentado dificuldade para processar a ordem seqüencial dos estímulos, podem ter se concentrado na decodificação e se esquecido de integrar o significado no todo, podem ter sentido dificuldade para criar um significado global e ordenar a informação segundo a lógica organizacional do texto, bem como as dificuldades podem ser oriundas de problemas de vocabulário. Esta pesquisa não oferece informações para saber em qual dessas possibilidades os alunos com dificuldades de escrita e compreensão de leitura se enquadram ou quais são as mais comuns. Entretanto, é um campo em aberto para outras investigações.

As dificuldades de aprendizagem na escrita encontradas podem ser oriundas de diversos fatores, tais como, dificuldade em reconhecer as formas, letras ou sílabas, e ao registrar a palavra aconteceriam as trocas, as inversões, as omissões. Um outro caminho é afirmar que não existe uma correspondência entre o léxico auditivo e a atribuição de significado semântico, ou seja, a dificuldade está em se fazer a correspondência 
entre o que se ouve e o que se deve escrever (Coll, Palacios \& Marchesi, 1995; Fonseca, 1995; Garcia, 1998; Sisto, 2001). Sisto (2001) afirma que outro fator a se considerar se relaciona com a facilidade e a rapidez na execução da escrita. Também ficam em aberto essas posições como fontes de explicação, mas talvez sejam bons indícios para explicar por que alguns alunos sem dificuldades na escrita a tiveram na leitura e vice-versa.

Um outro aspecto a ser ressaltado é que os erros na escrita dos alunos da terceira série estão se automatizando. Quanto mais automatizado o erro estiver, mas difícil se torna sua correção, uma vez que a forma assimilada é a forma errada. É relevante destacar a importância da avaliação das crianças, pois a investigação dos casos de dificuldade de aprendizagem no início do processo de escolarização minimiza suas conseqüências e possibilita sua superação antes de uma automação.

Uma das conclusões a que se pode chegar é que os alunos dessa escola não estão alfabetizados tal qual uma primeira série trabalhada por um alfabetizador experiente e competente tecnicamente. Talvez o grande problema de rendimento escolar seja decorrente do fato de que esses alunos ainda não adquiriram o código, não dominam as relações da escrita e da leitura. São os pseudo-leitores e pseudo-escritores. E as duas variáveis, aquisição do código ou do instrumental da escrita e a compreensão da leitura, parecem caminhar juntas, no sentido de que quanto mais se domina o código da escrita, há mais compreensão da leitura. Aparentemente pode-se supor que são duas construções que caminham juntas, na construção da escrita.

Esse contexto possibilita questionar a afirmação de que o aluno que escreve mal com o tempo, experiência e familiarização com o mundo letrado ele se autoalfabetiza. Os dados desta investigação indicam que eles não sabem escrever e também não compreendem o que lêem, levantando a questão de saber se a leitura sem compreensão estimulará o aluno a continuar sua participação no mundo letrado. Ao lado disso, é interessante lembrar que os alunos das terceiras séries estão piores ou iguais aos das segundas, e desvendar o por quê dessa situação não deixa de ser uma pesquisa interessante. Mas também reforça a dúvida colocada pois, apesar de mais um ano de escolarização, eles não estão muito diferentes em relação aos de uma série anterior.

Ao lado disso, aparentemente, essa não é a preocupação das últimas medidas adotadas pela educação, qual seja, Parâmetros Curriculares Nacionais e a Nova Lei da Educação. Em 1986 foi implantado o Ciclo Básico de Aprendizagem (CBA), determinando que as crianças seriam automaticamente promovidas da primeira série do ensino fundamental para a segunda série. O resultado foi, do ponto de vista do conhecimento do mundo letrado, no mínimo duvidoso, pois crianças que não dominavam a estrutura da escrita chegaram à segunda etapa do ciclo e nem os professores possuem infra-estrutura disponível, nem formação para dar continuidade ao trabalho. E isso foi considerado normal. Tal proposta foi reforçada pelos Parâmetros Curriculares Nacionais (PCN).

Para a maioria dos pais, bem como para seus filhos, o período de escolarização terá a exata duração da ausência da ajuda financeira em casa, que nas camadas economicamente menos favorecidas ocorre bem antes do previsto na lei. Repetindo a história, a partir do momento que tiverem que ingressar no mercado de trabalho, a escola ficará em segundo plano, muito mais se for associada à não-aprendizagem do conhecimento básico: "saber ler e escrever e fazer contas", como diziam antigamente.

\section{REFERÊNCIAS}

Batjes, K. \& Brown, T. (1997). Improving reading achievement of first grade students by integrating phonics skills into a whole language curriculum. Illinois: Saint Xavier University.

Bermejo, V. S. \& Llera, J. A. B. (1997). Dificultades de aprendizaje. Madrid: Síntesis Psicológica.

Berninger, V. W.; Abbott, R. D. \& Whitaker, D.; Sylvester, L. (1995). Integrating low and high level skills in instructional protocols for writing disabilities. Learning Disabilities Quarterly, 18(3), 293-309.

Braga, S. M. L. (1986). Produção de texto e o modelo operante: treino de repertórios específicos. Tese de doutorado, Universidade de São Paulo, São Paulo.

Brandão, M. L. (1992). O processo de leitura: algumas considerações teórico-práticas. Tecnologia Educacional, 21, 3-7.

Capellini, S. A. \& Ciasca, S. M. (2000). Avaliação da consciência fonológica em crianças com distúrbio específico de leitura e escrita e distúrbio de aprendizagem. Temas Sobre Desenvolvimento, 8(48), 17-23.

Capovilla, A. G. S. \& Capovilla, F. C. (2000). Problemas de leitura e escrita. São Paulo: Menon.

Cardoso-Martins, C. (1991). A consciência fonológica e a aprendizagem inicial da leitura e da escrita. Cadernos de Pesquisa, 76, 41-49.

Carelli, A. E. (1992). Teste da eficiência de programas em compreensão e leitura crítica. Dissertação de Mestrado, Pontifícia Universidade Católica, Campinas.

Coll, C.; Palacios, J. \& Marchesi, A. (1995). Desenvolvimento psicológico e educação - necessidades educativas especiais e aprendizagem escolar. Porto Alegre: Artes Médicas.

Deffenbaugh, S. A. (1997). Learning disabilities and reading personnel in Connecticut schools: system-level coordination. Connecticut: University of Hartford.

Dias, M. G. B. B.; Morais, E. P. M. \& Oliveira, M. C. N. P (1995). Dificuldades na compreensão de textos: uma tentativa de remediação. Arquivos Brasileiros de Psicologia, 47(5), 13-24.

Dockrell, J. \& Mcshane, J. (1997). Dificultades de aprendizaje en la infancia - un enfoque cognitivo. Buenos $\mathrm{Ai}$ res: Paidós. 
Garcia, J. N. (1998). Manual de dificuldades de aprendizagem - Linguagem, leitura, escrita e matemática. Porto Alegre: Artes Médicas.

Garrido, E. (1979). A técnica cloze e a compreensão da leitura. Dissertação de Mestrado, Universidade Estadual, Campinas.

Joly, M. C. R. A. (1999). Microcomputador e criatividade em leitura e escrita no ensino fundamental. Tese de doutorado, Universidade de São Paulo, São Paulo.

Jongsma, E. R. (1980). Cloze instruction research: a second look. Newark, Delaware: IRA.

Kragler, S. (1995). The transition from oral to silent reading. Reading Psychology, 16, 395-408.

Leffa, V. J. (1999). Fatores da compreensão na leitura. Universidade Federal do Rio Grande do Sul, Departamento de Línguas Modernas, Porto Alegre.

Lyon, R. G. (1998). The NICHD research program in reading development, reading disorders and reading instruction: a summary of research findings. A National Summit on Research in Learning Disabilities. National Center of Learning Disabilities, New York.

Molina, O. (1984). Avaliação da inteligibilidade de livros didáticos de $1^{o}$ e $2^{o}$ graus por meio da técnica cloze. Tese de Doutorado, Universidade de São Paulo, São Paulo.

Nunes, A. N. A. (1990). Fracasso escolar e desamparo adquirido. Psicologia: Teoria e Pesquisa, 6(2), 139-154.

Oliveira, G. C.; Sisto, F. F.; Souza, M. T. C. C.; Brenelli, R. P. \& Fini, L. D. T. (1994). Configuração cognitiva de crianças com dificuldades de aprendizagem em função de uma avaliação escrita de língua portuguesa. ProPosições, 5(1), 7-20.

Santos, A. A. A. (2001). A influência da consciência fonológica na aquisição da leitura e da escrita. Em F. F. Sisto; G. C. Oliveira; L. D. T. Fini; M. T. C. C. Souza \& R. P. Brenelli (Orgs.) Atuação psicopedagógica e aprendizagem escolar (6 ${ }^{\mathrm{a}}$ ed.), (p. 215-247). Petrópolis: Vozes.

Santos, A. A. A. (1981). Desenvolvimento do hábito de leitura e compreensão de textos através da aplicação de fichas: um estudo com adolescentes carentes. Dissertação de Mestrado, Pontifícia Universidade Católica, Campinas.
Schiefelbein, E. \& Simmons, J. (1990). Os determinantes do desempenho escolar: uma revisão de pesquisas nos países em desenvolvimento. Cadernos de Pesquisa, 35, 53-71.

Sisto, F. F. (2001). Dificuldades de aprendizagem em escrita - um instrumento de avaliação (ADAPE). Em F. F. Sisto; E. Boruchovitch; L. D. T. Fini; R. P. Brenelli \& S. C. Martinelli (Orgs.), Dificuldades de aprendizagem no contexto psicopedagógico (p. 190-213). Petrópolis: Vozes.

Taylor, W. (1953). Cloze procedure: a new tool for measuring readability. Journalism Quarterly, 3, 415-433.

Thomas, C. C.; Englert, C. S. \& Gregg, S. (1987). An analysis of errors and strategies in the expository writing of learning disabled students. Remedial and Special Education, 8, 21-30.

Tiosso, L. H. (1989). Dificuldades na aprendizagem da leitura e escrita: uma visão multidisciplinar. Tese de doutorado, Universidade de São Paulo, São Paulo.

Usova, G. M. (1978). A review of research on reading and learning disabilities. New York: Columbia University.

Vellutino, F. R. (1991). Introduction to three studies on reading acquisition: convergent findings on theoretical foundations of code-oriented versus whole-language approaches to reading instruction. Journal of Educational Psychology, 83(4), 437-443.

Vieira, M. A. R. \& Denhière, G. (1998). Compreensão de textos e classe social. Leitura: Teoria e Prática, 32, 3441.

Vinsonhaler, J. F. (1982). Diagnosing children with educational problems: characteristics of reading learning disabilities specialists and classroom teachers. Institute for Research on Teaching, Michigan: College of Education.

Weintraub, S. (1968). The cloze procedure. The Reading Teacher, 21(6), 567-607.

Whyte, S. S. (1985). The connection of writing to reading and its effect on reading comprehension. Massachusetts: University of Massachusetts.
Recebido: 25.05 .2002

Revisado: 14.10 .2002

Aceito: 01.11.2002

\section{Sobre os autores}

Karla Aparecida Zucoloto: Pedagoga pela Pontifícia Universidade Católica em Poços de Caldas. Mestra em Educação pela Universidade Estadual de Campinas. Atualmente realiza avaliações de crianças com histórico de dificuldade de aprendizagem para colégios particulares em Poços de Caldas e atende crianças com dificuldade de aprendizagem em escrita e leitura.

Fermino Fernandes Sisto: Pedagogo, doutor em Pedagogia pela Universidad Complutense de Madrid e Livre-Docente em Psicologia do Desenvolvimento pela Universidade Estadual de Campinas. Aposentado como professor Titular do Departamento de Psicologia Educacional da Faculdade de Educação da UNICAMP, atualmente é professor da Universidade São Francisco. Endereço para correspondência: Rua Carlos Guimarães, 150, ap. 82 - 13024-200 Campinas, SP - E-mail: ffsisto@ hotmail.com 